\title{
Onomatopoeic Infinitives and Nouns in EkeGusii: Evidence for imagic and relative iconicity
}

\author{
Elijah Omwansa Mariera * \\ (Kisii University, Kenya)
}

\begin{abstract}
Whether meaning is arbitrary or motivated remains a matter of unsettled linguistic debate. The main purpose of this discussion is to bring to linguistic attention the level of motivation in EkeGusii, a Bantu language of the Niger-Congo family spoken in Kenya, using onomatopoeic infinitives and nouns, and to attest that meaning is considerably iconic. It does not look convenient to classify onomatopes under ideophones. Imagic iconicity plays a central role in the two word classes, though imagic and relative iconicity intersect in cacophonous, reduplicative, and inherently onomatopoeic nouns. In EkeGusii, onomatopes are either explicit or implicit. It becomes clear that onomatopoeia acquires a metaphorical function in certain idiomatic expressions in EkeGusii.
\end{abstract}

Keywords: explicit and implicit onomatopoeia, parrot role, reflexive onomatopes, cacophony

\section{Introduction}

The situation surrounding iconicity has for many days been treated as peripheral in linguistic dialogue as observed by Dingemanse (2018). This scenario has rapidly changed with welcoming attention paid, by scholars around the globe, to iconicity in various languages. In this paper, I present evidence of such efforts around onomatopoeia first from previous research in a few languages, and then from EkeGusii, a Bantu language spoken in Kenya. Presenting iconicity as a conceptualization within semiotics, the study of signs (Bouissac, 1998), I argue that in EkeGusii onomatopes should not be treated as a subset of ideophones in as much as the roots of relevant words may be considered ideophonic. I then explain the concept behind imagic iconicity followed by evidence from data in three sub-sections, the last of which demonstrates that imagic and relative iconicity function contemporaneously. I then present an argument that onomatopes in EkeGusii should be classified into two kinds, explicit and implicit onomatopoeia, and finally, argue that onomatopes appear in certain metaphorical phrases in the language. Generally, this

* Elijah Omwansa Mariera: Department of Linguistics, Languages, and Literature, Kisii University, Kenya. E-mail: omwansaelijah@gmail.com. 
discussion presents evidence for iconicity from another language in East Africa to inform research and spearhead the debate.

\section{Evidence for the universality of onomatopoeia}

van Langendonck (2007) makes the following unfortunate remarks about onomatopoeia: "Compared to normal vocabulary, onomatopoeia remains a marginal phenomenon in natural language, though there may be differences in the degree to which it is implemented from one language to another". Such marginalization will be contested by data in support of onomatopoeic iconicity in EkeGusii, confirming that such sentiments have been overtaken. Dingemanse (2018) argues against attempts to treat as peripheral the iconic aspects of language like the iconicity in onomatopoeia and ideophones. It is still inopportune for van Langendonck to proceed with narrative in the following terms: "The more onomatopoeic words we get integrated in the linguistic system, the more they become symbolic and the more they lose their iconic value" (van Langendonck, 2007). Clearly, such remarks are not data-based, hence non-linguist, and are negated by van Langendonck's own illustrations on phonetic and morphological iconicity.

Contrary to van Langendonck's argument, Kirtchuk (2011) has availed evidence from Hebrew, showing that the language is highly onomatopoeic. Onomatopoeia permeates Hebrew lexicon and grammar deeply, widely and consistently. The many mappings between sounds and words identified include swift movements, tearing or stripping apart, dripping liquids, striking, piercing sounds made by a frightened person and many more. For instance, sounds $/ \mathrm{s} /, / \mathrm{z} /, / \mathrm{b} /, / 3 /$ suggest swift movements, and /bhl/ suggests dismay. Just like in EkeGusii, onomatopoeia in Hebrew is equally iterative (repetitive). Kirtchuk argues that onomatopoeia is the best exponent of iconicity, a part and parcel of language; a major devise in the understanding of language and the way it functions. Kirtchuk refers to Bolinger (1949), who observes that there is adequacy found in language, to some extent, between content and form.

Dofs (2008) raises evidence of iconicity in a comparative study based on English and Swedish animal sounds. The sound of a cat in English is meow, and mjau in Swedish. A cuckoo in English makes the sound cuckoo, and ko-ko in Swedish; a medium dog makes the sound [wu:f wu:f] in English, and [vuf-vuf] in Swedish; and a cow makes a sound [mu:] in English, and [mū] in Swedish. [Ku:] is the sound made by doves in English, which is [u:hu: u:hu:] in Swedish (Dofs, 2008:12). Several Examples of similar phonetic features between the sounds and animals are given as evidence of a degree of iconicity in the two languages. Dofs observes that even words that seem arbitrary at first glance have a particular sound in common. Even in Swedish and English, reduplication is a common feature of onomatopoeia. Notably, a number of onomatopoeic words are now 
conventionalized. For instance, in the Oxford Advanced Learners Dictionary, the English word coo also means, "to say something in a soft, quiet voice, especially to somebody that you love" (Wehmeier, 2000). Though Dofs argues that with extensive conventionalization of onomatopoeic words, iconicity seems to be lost, the valid point should be that the iconic nature of the words tends to fade at the sub-conscious level of the speaker, but it remains very clear, highly interesting and informative to linguistic investigation, shedding indispensable light on the nature, origin, and function of language.

Pertiwi (2015) shows that the translation of Indonesian words to English displays that in both languages, there is evidence of iconicity. Indonesian aaahm translates to 'yawn'; $\mathrm{hmm}$ to 'hmm', expressing doubt or hesitation; tok tok to 'knock knock', for a nock with knuckles; haeek to 'yuck', expressing disgust; krak krak to 'crack crack', for breaking into cracks; kraus to 'crunch', for the crushing of something with teeth; and plup to 'plop', for the sound of a small object falling into water. Although Pertiwi appears to mix onomatopes and ideophones, the concept of mimicry is clearly demonstrated in the two languages. Interestingly, the word for 'yawn' in EkeGusii is okwaaora \{o-ko-aaor-a\}, and despite the non-identical sequences compared to English and Indonesia, the root sounds onomatopoeic. Iconicity therefore cannot be warranted on the basis of identical sound sequences between two or more languages, as implied in Dofs (2008), but on the basis of mimicry or mimesis as cognitively interpreted by the speakers of a particular language. Therefore, a rooster's [kokıdu:dldu:] in English, and the Swedish [kukklikū] (Dofs, 2008:13), are actually onomatopoeic, and therefore motivated, in their respective languages.

Ma (2018:51) gave examples in Chinese dialects like mandarin and of words like the noun $m \bar{a} o$ 'cat' which originates from miāo 'the cry of the cats'. Further examples of cat

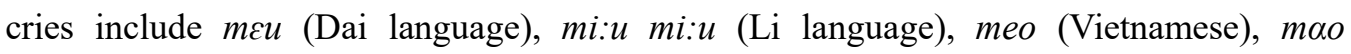
(Persian), and mйao (Czech) among many cited by Ma. These are comparable to the English meow, and the Swedish mjau in Dofs (2008), and to sound [y-] in njau 'meow', and njau 'cat' of Jingpho, one of the Sino-Tibetan, Tibeto-Burman languages (Dai \& Xu, 1995:125 in Ma, 2018:49). Assaneo, Nichols and Trevisan (2011:5) in examining click and knock-type onomatopoeias show that the sound $/ \mathrm{k} /$ is common among eleven languages in the words associated with the action. For instance, the English onomatope nok for knocking is tok in Spanish, Italian, and French. It appears as kon in Japanese, klop in Dutch, kop in Hungarian, and kok in Thai, among others. Beyond the related ways of imitation of similar sound sources, it is clear that onomatopoeia is a universal aspect of human language. Following He (2008), it can be argued that onomatopes (or ideophones) have universal features that may allow to be perceived as the memes (or 'genes') of cultural and language evolution as certain common features have been passed down generations of the human race. 


\section{A conceptualization in semiotics}

That there is a natural relationship between a sound and its meaning, as opposed to the arbitrary is the core idea in the conceptualization of iconicity, as Fordyce (1988:8) observes. Chandler (2002) reiterates that semiotics is concerned with everything that can be taken as a sign; signs take the form of words, images, sounds, gestures, and objects. On the other hand, Bouissac (1998:293) defines Iconicity as "a semiotic notion that refers to a natural resemblance or analogy between the form of a sign ('the signifier', be it a letter or sound, a word, structure of words, or even the absence of a sign) and the object or concept ('the signified') it refers to in the world or rather in our perception of the world". In onomatopoeia, iconicity may be narrowed down to there being, not words, but imitative elements within words (Assaneo, Nichols \& Trevisan, 2011), 'onomatemes' according to Ma (2018). Whilst semiology (the science of signs) is associated with Ferdinand De Saussure, Semiotics is associated with Peirce (1931), in the framework of general theory of signs (Nöth, 2001). It follows Saussure's observation that onomatopoeia was relatively motivated as noted by van Langendonck (2007).

\section{Onomatopes versus ideophones in EkeGusii}

A major challenge to linguistic investigation lies in the tendency to use the terms 'ideophones' and 'onomatopoeias' interchangeably, so that what are ideophones in one language might be onomatopes in another, while other scholars feel one of these two is part of the other. This does not look tenable for EkeGusii, especially if one pays attention to the semantics, syntactic distribution, morphological structures, and the phonetic features of sound imitative words (detail in Mariera, forthcoming).

Sound imitation appears a core (but not the only) feature to both ideophones and/or onomatopoeic words (see Dingemanse's (2018) misconceptions). Quoting Samarin (1965), Dingemanse (2018:4) observed that “...ideophones depict many aspects of sensory scenes beyond sound, and onomatopoeia make up only a minor portion of most well-described ideophone inventories". The challenge posed by such a claim as regards EkeGusii lies in the characteristics that may not accommodate two groups of lexical items under ideophonicity. Firstly, ideophones appear morphologically limited, receiving only an optional nominalizer or adverbializer morpheme (Mariera, forthcoming). On the other hand, onomatopoeias are equally sound imitative but they are completely lexicalized in the language system to a level that such items agree with the morphological structures outlined in Nash (2011), and Cammenga (2002), mainly for EkeGusii nouns and infinitives. The infinitive and the noun are used to demonstrate that unlike ideophones which can be sheer sound sequences like/ffff/, onomatopes are fully lexicalized and analyzable as below. 
Elijah Omwansa Mariera

\begin{tabular}{|c|c|c|c|c|}
\hline (1) $o-$ & go- & togot & $-a$ & ([oyotoyota $]$ ) \\
\hline Pre-Prefix & Class Prefix & Root & FV & \\
\hline \multicolumn{5}{|c|}{ 'to boil, of water; or to bubble, of boiling water' } \\
\hline (2) $e_{-}$ & $b i-$ & chuchu & & $([\mathrm{e} \beta \mathrm{itfutfu}])$ \\
\hline Pre-Prefix & Class Prefix & Stem & & \\
\hline NOM & NOM & & & \\
\hline 'chicks' & & & & \\
\hline
\end{tabular}

It should be noted that this particular infinitive does not include the object marker and the extender morphemes as shown in Nash (2011), but the basic morphological structure is reflected.

Secondly, while ideophones display wider semantic and syntactic versatility (they may function as exclamatives, adverbs, nouns or clausal elements), onomatopes are rigid members of distinct word classes that carry particular and conservative semantic and syntactic functions, and can only be isolated from the rest of the arbitrary signs on the basis of their iconic features. Precisely speaking, they display weakened or covert 'ideophonic characteristics', only identifiable within their roots; the levels of motivation in onomatopes are more obscure than in ideophones. This may agree with Ma's (2018:52) observation that "onomatopoeia is an important sign of quasi-language evolving into real language, after which the function of language turns from expressing feelings to knowledge". Going by Samarin's position (if onomatopes are treated as part of ideophones), it would necessitate that we divide EkeGusii 'ideophones' into two types, which appears linguistically cumbersome, imprudent, and threatening to retrograde towards the marginalization that Dingemanse (2018) has fairly pushed out of place. This discussion therefore is focused on the later set of items that are classified under onomatopoeia, and which may not be treated as a sub-set of ideophones.

Finally, the versatility associated with ideophones may be compared to their variable nature, that they are context-dependent, group-bound, can be individualized, and can vary from signer to another, whose features are not associated with onomatopes. Signers are likely to come up with new ideophones with the changing world, and quite a number have probably been abandoned but onomatopes like ebichuchu 'chicks', and ogotogota 'to boil' are enduring parts of the lexicon. Generally, it can be argued that while the motivation in onomatopes is somewhat obscure, it remains more obvious in ideophones regardless of their higher levels of versatility and variability.

\section{Imagic iconicity in EkeGusii onomatopes}

The concept behind imagic iconicity is that of a word mimicking a sound in the real world. One of the forms of this type of iconicity noted by Smoll (2014) is onomatopoeia, 
and of course, ideophonicity. Smoll gave examples of animal calls, laughing, sounds related to water, running, light and heavy footsteps, throws, swallowing, and walking among others. Both onomatopes and ideophones are mainly examples of imagic iconicity, but the immediate focus is on onomatopes as distinguished in Section 4 (above), to avoid overlap with ideophones in EkeGusii, the reduplicative, exclamatory adverbs, discussed in Mariera (forthcoming).

\subsection{Imagic iconicity in onomatopoeic infinitives}

One of the household terms among the Kenyan families is kususu, a Swahili slang and euphemism for kukojoa 'to urinate', used when talking with children. The sibilant sounds /s-s/ in the word are actually imitative (echoic) of the sound from the act. English 'poo poo', which sounds onomatopoeic, has equally been nativised into slang as kupuирuu, and is used with children to refer to the act of going for a long call. According to Ely (2005), word acquisition in early childhood often refers to onomatopoeic expressions, because their inherent echoic relation to a referent enhances apprehension. van Langendonck (2007) describes onomatopoeia as articulatory mimesis. Schmidtke, Conrad \& Jacobs (2014) observe that sound-meaning mappings are more established in onomatopoeia, idiophones, and phonaesthemes. They observe that onomatopes may express emotion or sentiment on the part of the speaker; onomatopes are used to lend a voice to bodily feelings and effects.

The data in Table 1 is an exploration of a few of the many lexical items built on onomatopoeic roots in EkeGusii. In all the examples, the roots, with extenders, have been separated from pre-prefixes, class prefixes, reflexive morphemes, causative morphemes, and final vowels, to allow the roots in boldface to stand out for ease of focus on the onomatopoeic sounds of interest. This is not a morphological engagement but an endeavour to clarify analysis and make it convenient. The twenty-six examples demonstrate, besides the reality of iconicity, the echoic wealth and magnificence of EkeGusii. The combinations of consonants and vowels in each of the roots may convey, even to a non-speaker of EkeGusii, its imitative sound features on relating the sound sequences to the meanings in the glosses.

Table 1. Onomatopoeic infinitives

\begin{tabular}{|c|c|c|c|}
\hline $\mathrm{S} / \mathrm{N}$ & Infinitive & Transcription & Gloss \\
\hline$(3)$ & $o-k o-b e r-a$ & [okoßera] & 'to boil of milk' \\
\hline$(4)$ & ogo-sanonok-a & [oyasanonoka] & 'to make noise of melting fat' \\
\hline$(5)$ & $o$-go-sarorok- $a$ & [oyosaroroka] & 'to melt, of fat' \\
\hline$(6)$ & $o-k o-g o n-a$ & [okวyวna] & 'to snore' \\
\hline$(7)$ & $o-k o-r u m-a$ & [okoruma] & 'to grumble' \\
\hline (8) & $o$-go-sinyor- $a$ & [ogosijəra] & 'to urinate' \\
\hline
\end{tabular}


Elijah Omwansa Mariera

\begin{tabular}{|c|c|c|c|}
\hline$(9)$ & $o-k w-e-m i r-i-a$ & [okuemiria] & 'to blow nose' \\
\hline$(10)$ & oko-nach-a & [okonatfa] & 'to cut' \\
\hline$(11)$ & $o$-go-twang- $a$ & [oyotuanga] & 'to beat' \\
\hline (12) & $o-g o-c h w a t-a$ & [oyotfuata] & 'to beat' \\
\hline$(13)$ & $o-g o-c h w a n-i-a$ & [oyotuania] & 'to whip' \\
\hline (14) & $o-g o-t i r-i-a$ & [oyotiria] & 'to caper, of a calf' \\
\hline (15) & $o-k o-r o k-a$ & [okoroka] & 'to puke/vomit' \\
\hline$(16)$ & $o-k o-i n y i a m b-a$ & [okoiniamba] & 'to fart' \\
\hline$(17)$ & $o$-go-sigik-i-a & [oyosiyikia] & 'to rub, apply friction' \\
\hline$(18)$ & $o$-ko-garagar- $i-a$ & [okoyarayaria] & 'to cause an irritating taste, or to annoy' \\
\hline (19) & $o-k w-e-\boldsymbol{g o g}-i-a$ & [okuعуəyia] & 'to gurgle, attempt to puke' \\
\hline$(20)$ & $o$-go-kurur-a & [oyokurura] & 'to drag on a surface' \\
\hline$(21)$ & $o$-ko-geker-i-a & [okoyekeria] & 'to cluck, of a layer hen' \\
\hline$(22)$ & $o-g o-$ chon- $i-a$ & [oyotgonia] & 'to milk drying teats' \\
\hline$(23)$ & $o$-go-koror- $a$ & [oyəkorora] & 'to cough' \\
\hline$(24)$ & $o-g o-s a-a$ & [oyosaa] & 'to diarrhea' \\
\hline$(25)$ & $o-k w-e-u \boldsymbol{m}-i-a$ & [okueumia] & 'to lament' \\
\hline$(26)$ & $o-k o-n y e n y-a$ & [okojejna] & 'to cut with a knife' \\
\hline$(27)$ & $o-k o-n y u g a n y u g-a$ & [okonuyajuya] & 'to shake and weaken' \\
\hline
\end{tabular}

A discussion of sampled examples from Table 1 above demonstrates the levels of iconic mappings between the infinitival words and their referents. o-go-togot- $a$ 'to bubble, of boiling water' in (1) occurs also in Kiswahili as ku-tokot-a, only that in EkeGusii the velar stop in the root has undergone voicing and subsequent lenition, being vowel-sandwiched. In both languages, the root is mimetic of the bubbling noise made by boiling water, porridge, or other food cooked by boiling. The speaker assumes to hear noise with the sounds $/ \mathrm{t}$ y $/, / \mathrm{toy} /$ as recurrent hence the formation of the word. The word o-ko-gon- $a$ in (6), already has a voiced velar fricative $[\gamma]$ followed by a mimetic vowel sound [0] and then a voiced alveolar nasal [n], all related to the parts of the vocal tract associated to the origins of snoring noises, therefore echoing the very noise. There is nothing arbitrary about this sound sequencing. Rather, it is perceptuo-motor involvement that has come up with such a "word". Technically speaking, there is no "word" in this lexical item other than a one-to-one sound mapping between the word and the sounds of the spontaneous act. (19) with $o-k w-e-g o g-i-a$ 'to gurgle, or attempt to puke', is already glossed with an onomatopoeic English equivalent. The two share related sounds $[\mathrm{y}]$ and $[\mathrm{g}]$, showing the universal nature of phono-iconicity. The voiced velar consonants sandwiching the back lower-mid vowel are actually imitative of gurgling or any attempt to force oneself to puke, 
especially by inserting fingers to the back of the oral cavity. The actual event is nearly 'heard' in (15) if someone actually vomits. Each gush-out of stomach contents is heard to sound like the imitative root sequences which suggest a pattern like /rrrosok/. This is fairly comparable to the word in (23), o-go-koror-a 'to cough', with similar consonants regardless of sequence, related to common places of articulation, since in both cases the gullet is the point of action.

o-go-sinyor-a [oyosinora] 'to urinate' in (8), may be used to discuss the relationship between the sequences and the meaning components. The root in bold-face has the consonants $/ \mathrm{s} /, / \mathrm{n} /$ and $/ \mathrm{r} /$. The first sound, the alveolar fricative is a sibilant whose turbulence conveys the initial stage of urination with a [GUSH], implying the jet-like start as a result of full bowel pressure. The following sound, an alveo-palatal nasal may be assumed to convey the meaning component [SMOOTH] as a result of reduced pressure, implying reduced friction, yet retaining the continuity of the act by its continuant and approximant nature. The final alveolar flap sound marks the end point of the act of urination, suggestive of the fill-up noise of the erosive, temporal and foamy [POOL], especially on loose ground before the urine percolates. This noise becomes clearer as the bladder gets drained. Generally, the root of this infinitive maps the act of urination from the start to the end of sounds that tend to convey the relevant meaning components, making it purely onomatopoeic. Any other infinitive like (23) o-go-koror-a [əyəkərora] 'to cough', can be analyzed by examining the initial root sounds, the nature and order of the sounds. Coughing is a reflex-controlled activity which attacks with a sudden [BURST] represented by the velar plosive $/ \mathrm{k} /$. A productive cough allows mucus in the pipe which is represented jointly by the vowel / $\mathrm{o}$ and the recurrent rolled sound / $/$ / as one tries to push out the lump. The rest of the affixations are the ordinary morphemes that change word classes as shown.

Perhaps it is important to note that certain nouns like (50) a-ma-kororo [amakororo] 'phlegm' are derived from such finite verbs as korora [korora] 'cough', which is also the stem for the infinitive in (8), ogokora, both occurring as a result of affixation. The discussion on onomatopoeic nouns complements the picture of onomatopoeia being a richer meaning relation way that cannot be imagined outside of research. Generally, each of the infinitives in Table 1 is purely onomatopoeic and the meaning components are thus analyzable.

\subsection{Imagic iconicity in onomatopoeic nouns}

To demonstrate the function of onomatopoeia in the EkeGusii noun class, the data in Table 2 have the prefixal forms, the augment and class markers separated by hyphens, leaving the stems intact since the final vowels all sound to be meaning-carrier parts of the nominal onomatopes. The data are arranged in such an order that creature-related onomatopes are reflected in (2) and (28-40), object-related onomatopes in (41-46), an event 


\section{Elijah Omwansa Mariera}

related onomatopes in (47), reflex-controlled onomatopes in (48-51), and an echoic noun in (52).

Table 2. Onomatopoeic nouns

\begin{tabular}{|c|c|c|c|}
\hline $\mathrm{S} / \mathrm{N}$ & Noun & Transcription & Gloss \\
\hline$(28)$ & chi-ngi & [tfi:ngi] & 'flies' \\
\hline$(29)$ & $e$-bi-siriri & [eßisiriri] & 'crickets' \\
\hline (30) & $e$-bi-chuni & [e $\beta$ itfuni] & 'fruit flies' \\
\hline (31) & ri-bururu & [rißururu] & 'locust' \\
\hline (32) & e-ngoko & [Ejgoko] & 'hen' \\
\hline (33) & e-ge-chibi & [eyetfi $\beta \mathrm{i}]$ & 'song bird' \\
\hline (34) & a-ma-chore & 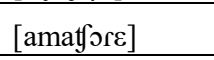 & 'weaver birds' \\
\hline (35) & e-kong'a & [ekoya] & 'crown bird' \\
\hline (36) & $e$-moori & [Emo:ri] & 'calf, young of a cow' \\
\hline$(37)$ & e-ke-gonkooru & 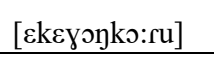 & 'crow bird' \\
\hline$(38)$ & e-barara & [eßarara] & 'marabou stork' \\
\hline (39) & e-gi-oto & [eyiots] & 'frog' \\
\hline$(40)$ & e-ge-chuguchugu & [eyetfuyutfuyu] & 'a bird that makes noise when flying' \\
\hline (41) & $e$-bi-taratara & [eßitaratara] & 'slippers/sandals' \\
\hline$(42)$ & e-ke-ngere & 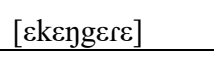 & 'bell' \\
\hline (43) & e-konu & [ekonu] & 'mortar' \\
\hline (44) & chi-n-chigiri & [tgintfiyiri] & 'shakers' \\
\hline$(45)$ & e-ge-chunchugo & [egetfuntfuyo] & 'sieve' \\
\hline (46) & e-ke-nyororia & [ekejororia] & 'dripping water' \\
\hline (47) & e-keero & {$[\varepsilon \mathrm{k \varepsilon \varepsilon ro]}$} & 'capped palm for feeding with porridge' \\
\hline (48) & a-ma-sinyoro & [amasinюro] & 'urine' \\
\hline (49) & a-ma-miria & [amamiria] & 'mucus' \\
\hline$(50)$ & a-ma-kororo & [amakorəro] & 'phlegm' \\
\hline$(51)$ & a-ma-te & {$[\mathrm{amat} \varepsilon]$} & 'saliva' \\
\hline$(52)$ & e-gi-ateko & [eyiateko] & 'breakage or outbreak' \\
\hline
\end{tabular}

As demonstrated under infinitives, onomatopoeic lexical items are literally based on mimicry, guided by the auditory impressions inscribed on the hearer's mind. In (2) for instance, from perceived chick sounds, speakers combine and duplicate the alveo-palatal affricate $/ \mathrm{t} \mathrm{u} /$ and vowel sounds $/ \mathrm{u} /$ in the root, then add the nominal class marker morpheme ge-, whose (plural form is $-b i$-), and the augment (or nominal pre-prefix) $e$-, to lexicalize the string into a functional item, egechuchu [eyetfutfu] 'chick' or the plural 
ebichuchu [eßttfutfu] 'chicks'. The affricate implies the strenuous passage of resonated air through the narrow chick pipes, mimicking the noisy airflow by its fricative nature and continuant tendency. The voiced $/ \mathrm{u} /$ makes the impression of a cry. The reduplicate sequence conveys the meaning component [THIN CRY]. To this iterative pattern, the augment $e$ - and the class marker ge- are affixed to derive the noun from the onomatopoeic root. Technically speaking, the expected final vowels are not affixed but are replaced by the onomatopoeic vowels that come last, possibly serving a morpho-phonological function.

In (31), the speakers perceive sounds $/ \mathrm{p} /$ and $/ \mathrm{r} /$ in the movement of the locust ${ }^{\mathbb{1}}$ as in making a sound string close to [p-r-r-r], with a plosive and trill sequence. These sounds could be maintained if the movement of the locust were described in an ideophone. The voiceless plosive undergoes lenition and voicing resulting in the bilabial fricative $/ \beta /$, while the trill changes to a flap in noun formation. The new string of sounds should be $[\beta-\Gamma-r]$, but with phonotactic demands, the vowel sound $/ \mathrm{u} /$ is selected as the mimetically closest to perceived movement sounds. The resultant root [ $\beta$ ururu] conveys the meaning components [VIBRATION] and [CHIRPING] to imitate the noise created by the rapid snapping of wings as the locust moves. This onomatopoeic root allows affixation of the prefix ri- to form the noun ribururu [rißururu] 'locust', which refers to the solitary insect. Such mappings are possible for all the creature-related onomatopes in Table 2.

The reduplicated sequence [tar] in (41) is imitative of the sound made from sandals when one is in motion. As one pulls up the foot to take a yard, the elastic Y-shaped straps pull the loose and light rubber sole which gently taps the lower back side of the heel. With alternation between the right and left legs, the whole journey orchestrates a flip-flop kind of rhythm which earns the footwear its name, implied in the reduplication of the onomatopoeic root $[\operatorname{tar} \operatorname{tar}]$. This conveys the meaning component [TAP TAP]. With affixation, the noun formed is therefore ebitaratara [eßitaratara] 'sandals'. Since sandals are not culturally original Gusii artifacts, the speakers are bound and justified to imitate the noise to derive new words as a word formation process.

(52) has two plosives in the root, $/ \mathrm{t} /$ and $/ \mathrm{k} /$, suggestive of an explosion, eruption or a blast when something breaks. The two plosives convey meaning components such as [BURST], [EXPLODE] or [RUPTURE]. (40), e-ge-chuguchugu, appears as an entry in the Authoritative EkeGusii Dictionary: endabaro endabasia y'ekegusii, Bosire \& Machogu (2013:268), with an explanation as "a type of bird which makes 'chuguchugu chuguchugu' sounds when flying". Though no more information is given in Bosire \& Machogu, the

\footnotetext{
(1) The translation 'Locust' is used instead of grasshopper to avoid confusion. Locusts of the species locusta migratoria are known to move in a destructive swarm and in EkeGusii they are known as chingige. A solitary locust is never referred by the singular term engige as would be expected but is usually called ribururu. Information on locusts is available on https://www.nationalgeographic.com.
} 
reference targets a small, brownish bird with a long tail, comparable to the scissors-tailed hummingbird whose snapping wings tend to whistle on flight. However, the term appears to be a regiolectical reference as random questioning shows that many speakers do not seem to agree on the bird referred to, leave alone identifying it. The transcription of the noun, as given in Table 2, makes it clear that the noun is imitative of the sounds made by the shattering of wings. Such morphophonological mappings are manifest throughout the rest of the lexical items based on animal and insect sounds, raising the curtains on the Saussureian claims on the arbitrary nature of signifiers of denotata.

It can be demonstrated that onomatopoeic roots, compared to iconic ideophones (Mariera, forthcoming), are a more fertile ground for affixation as a word formation process in EkeGusii, since related nouns, infinitives and finite verbs can be built on common onomatopoeic roots as demonstrated using the root in (49), which is onomatopoeic of the sound of nose blowing. The inflection of the roots is advanced to ordinary morpheme combination patterns as shown.

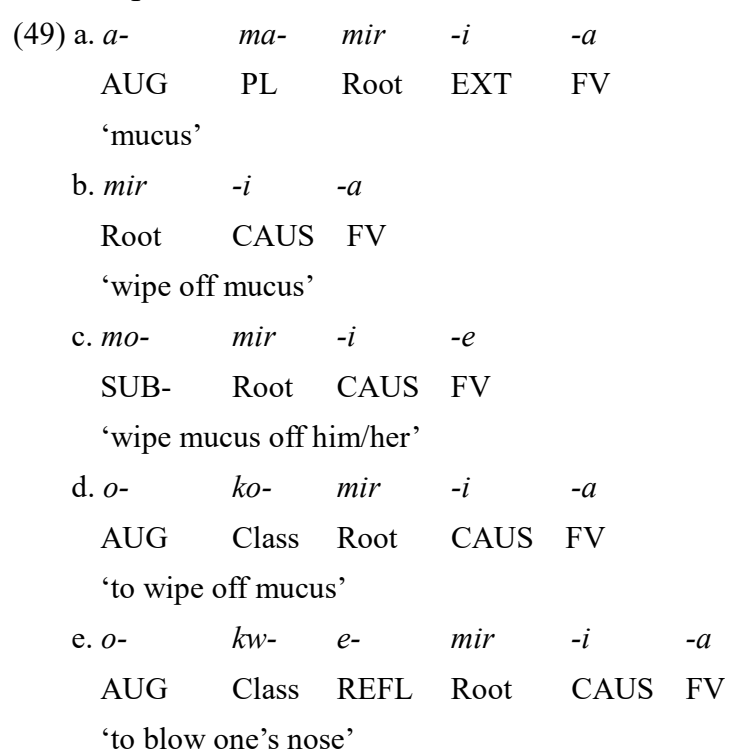

All the examples discussed here suggest the need to investigate the extents of linguistic motivation in other languages. Perniss, Thompson \& Vigliocco (2010) observed that onomatopoeia is limited to sounds, especially animal sounds, objects in motion or sounds upon impact on other objects, which may in other circumstances exhibit phonaesthesia. They give examples from English like "whoosh, swish, whack, crack, crash, bang", all onomatopoeic. Maeder, Fischer \& Herlofsky (2005:177) placed onomatopoeia under imagic iconicity, where "there is a more or less direct one-to-one relation between the linguistic 'sign' (usually a stem, i.e. a morphologically unstructured form) and the 
'signified". They gave sounds like Al-falaq from Arabic which have fricatives and stops showing movement through a narrow cavity followed by a final explosion as a way of mimicking reality. The order of consonants in Arabic shows a three-fold sequential action of splitting: xalaq 'creates', waqab 'flows', Guqad 'knots' and hasad 'envies' (Maeder, Fischer \& Herlofsky, 2005:178).

\subsection{Imagic and relative iconicity in onomatopoeic nouns}

There is evidence of phono-iconicity and reduplication in EkeGusii as a result of sounds that may be termed cacophonous. Cacophony relates to auditory unpleasantness as a result of sounds being discordant. Cacophonous sounds are therefore associated with words that are auditorily repulsive. The parts of words where such sound sequences occur are reduplicated, which enables EkeGusii to communicate negative meanings by way of consequential dissonance. The reduplicated stem parts, in a sense, are non-words but to native speakers they carry context-dependent meaning components enhanced by reduplication.

This scenario, dubbed phonosymbolic cacophony, may be exemplified by the data in Table 3 which has nouns with such sequences. A few of the nouns and the glosses are from Bosire \& Machogu (2013), and the rest from respondent information. While phonesthesia is also existent in reduplicative infinitives in EkeGusii (Mariera, forthcoming), the focus here is on 'metaphorical onomatopoeia' and sound symbolism, where imagic iconicity and relative iconicity seem to work concurrently.

Table 3. Cacophonous, iterative and inherently onomatopoeic nouns

\begin{tabular}{|c|c|c|c|}
\hline $\mathrm{S} / \mathrm{N}$ & Noun & Transcription & Gloss \\
\hline (53) & e-sagasaga & [esayasaya] & 'chaos or undefined noise' \\
\hline (54) & e-segesege & 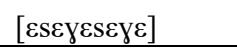 & 'unpleasant happening' \\
\hline (55) & e-obaobe & {$[\mathrm{eo} \beta \mathrm{ao} \beta \mathrm{e}]$} & 'fracas or pandemonium' \\
\hline$(56)$ & e-sosobe & [esoso $\beta \mathrm{e}]$ & 'fear or extreme fear' \\
\hline (57) & e-samusamu & [esamusamu] & 'disease causing skin rash' \\
\hline$(58)$ & e-buruburu & [eßurußuru] & 'noisy conflict' \\
\hline (59) & e-burukano & [eßurukano] & 'untidy situation/disorder' \\
\hline$(60)$ & e-ruchano & [erutfano] & 'a mixed up situation/pandemonium' \\
\hline$(61)$ & e-kobakobe & [ekoßakoße] & 'disorder/chaos' \\
\hline$(62)$ & o-bo-kayayu & [oßokajaju] & 'promiscuity' \\
\hline$(63)$ & o-bo-chorochombu & [obotforotfombu] & 'abject poverty' \\
\hline
\end{tabular}

The reduplicating stem consonant sequences in Table 3 are $/ \mathrm{s}-\gamma /, / \beta-\beta /, / \mathrm{s}-\mathrm{s}-\beta /, / \mathrm{s}-\mathrm{m} /$, $/ \beta-\mathrm{r} /, / \beta-\mathrm{r}-\mathrm{k} / / \mathrm{r}-\mathrm{f} /, / \mathrm{k}-\mathrm{j} /$, and $/ \mathrm{f}-\mathrm{r} /$, respectively. Apart from (55) which has stem parts that sound, perhaps, derived from the interjection obe 'Oh', used to show shock, surprise, or 
disappointment, the rest of the reduplicative parts may be argued to be non-words on their own, which though, attain meaning in such strings of stem reduplication following subject markers that nominalize them.

The unpleasantness of the sound patterns in relation to the meanings conveyed by the words all show evidence of iconic mappings between the forms of the nouns and their meanings. The cacophonous properties of the consonant sequences conform to the auditory and visual experiences of the situations depicted by the nouns. For instance, in (53), e-sagasaga [esayasaya] 'chaos or undefined noise', the alveolar fricative makes turbulence suggestive of [COMMOTION] and the articulation proceeds to a velar fricative suggestive of [FRICTION]. Once this stem is reduplicated, it conveys the repetition or the durative nature of a chaotic situation. Of course, this noun may arguably be inherently onomatopoeic in the sense of initially being derived from environmental noises, but the application fits the meaning components conveyed. The same is applied to (54).

A related observation may be made from (58) which has the bilabial fricative $/ \beta /$ in the stem-initial position and $/ \mathrm{f} /$ in the stem-final position before it undergoes reduplication with the intervening segment $/ \mathrm{u} /$. The consonant-vowel sequence conveys [DISORDER] which is inherently implicit onomatopoeia (detailed in Section 6, below). The same meaning component appears in the first part of the stem of (59). The sound patterns are indeed unattractive or unpleasant. (60) e-ruchano [erutgano] 'a mixed-up situation', has a flap at the stem initial position suggesting inherent disorderly noise, and with a sibilant alveo-palatal affricate, the noise is augmented enough to convey the meaning of a mixed-up situation, or pandemonium.

According to Persnis, Thompson \& Vigliocco (2010), a wider range of sensory events can be accommodated into sound-symbolic mappings, including manners and types of motions, physiological and psychological states, tactile, mental and emotional experiences. Maeder, Fischer \& Herlofsky (2005) compared words to sketches, maps, charts, graphs, and pictorial diagrams that show relationships between sounds and meaning. Sound-meaning mappings have already been exemplified in the preceding sections.

\section{Explicit and implicit onomatopoeia}

Following the data presented in Tables 1 and 2, it is here proposed, a priori, a classification of the onomatopes in EkeGusii into two basic kinds: explicit (transparent) and implicit (metonymical) onomatopoeia.

Explicit onomatopoeia can be considered a form of imitation of sounds from the source. This form may be viewed as express, since the sounds are derived from the origin. The speaker assumes the role of the originator of the sounds by playing some forms of parrot responsibility; a play-back form of reenacting the noise made by the source, though in 
human sounds. For instance, the words emoori [emo:ri] 'calf', ebichuchu [eßitfutfu]

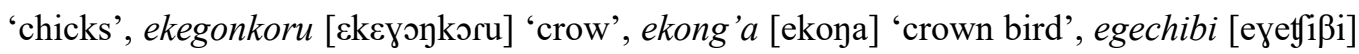
'song bird', and okogona [okəyəna] 'to snore', are plainly imitative of the sounds made by the calf, the birds, or the snorer. Explicit onomatopoeia is more transparent especially to the native speaker as they can expressly understand the direct imitation of the sounds picked from the source. This kind of onomatopoeia involves minimal cognitive processing as the brain replicates, in the human fashion, the perceived auditory impressions. This explains why sounds of an animal like a dog may have similar sound patterns from an African language to a European language, as illustrated at the end of this section.

Implicit onomatopoeia, on the other hand, is the form of imitation of sounds activated in the cognitive 'ear' of the speaker as perceived. This second form can be viewed as associative or metonymical since the speaker generates human sounds that can fairly imitate (or represent) the noise triggered by an associated action, movement or noise, to name the trigger (the animal, thing or object). For instance, words like ogosinyora [ogosinora] 'to urinate', egechuguchugu [eyetfuyutfuyu] 'type of a bird', and amamiria [amamiria] 'mucus', are examples of implicit onomatopoeia, since the speakers imitate what they approximate to be the sounds they perceive during urination, or when the bird moves, or when one blows his or her nose. Comparatively, this form of onomatopoeia can be termed a little opaque since it is less directly imitative compared to explicit onomatopoeia. The parrot role in explicit onomatopoeia is here replaced by replication of perceived auditory impressions in terms of approximate sounds. This form of onomatopoeia involves a higher degree of cognitive processing since the brain is engaged in a kind of sound equation-and-marching search, locating the fairest equivalents of the perceived auditory impressions. This explains why individual speakers of the same language may reenact sounds variously in relation to the same concept.

Of the two envisioned kinds of onomatopoeia, explicit onomatopoeia appears more limited to living things and such roots are comparatively less productive for affixation as a word formation process. Of all the Examples in Table 1, about 6 out of 26 are explicit onomatopes while in Table 2, about 11 out of 26 are explicit onomatopes. On average, about $32 \%$ of the data in Tables 1 and 2 contains explicit onomatopes. On the other hand, about $68 \%$ are implicit onomatopes. Therefore, metonymical onomatopoeic roots, based on their numbers, are more available to affixation of inflectional morphemes for purposes of word formation.

The major challenge with this kind of classification lies in the lack of straightforward criteria to help distinguish between onomatopes that belong to either side. For instance, onomatopes referring to reflex-determined and spontaneous processes like farting, coughing and vomiting appear partially transparent and reflexive (in the sense of 
self-mimicking), though they are considered to belong more to explicit than implicit onomatopoeia. A word like o-go-sa-a [oyosaa] 'to diarrhea', arguably, may not clearly belong to either kind, as the word itself sounds partially imitative of the actual sound in the act, though again based on its approximate and variant nature, it can be considered implicit onomatopoeia. This classification of onomatopoeia is more of an ignition of a language-specific and potentially universal intellectual debate than a conclusive position, since languages vary in their treatment of words and sounds. However, this looks plausible for purposes of linguistic analysis, hypothesizing and suggestions for future investigations in other languages.

The hypothesized division of onomatopes into the two basic kinds is evidenced in comparative data from other languages. For instance, Rungrojsuwan (2009) avails evidence of similarities of the lexicon in six languages in the onomatopes that refer to [DOG'S BARK] as follows.

$\begin{array}{ll}\text { Language } & \text { Phonetic Forms } \\ \text { English } & \text { /baw waw/ } \\ \text { German } & \text { /wau wau/ } \\ \text { Spanish } & \text { /gua gua/ } \\ \text { Italian } & \text { /bau bau/ } \\ \text { Thai } & \text { /hôn hôy/ } \\ \text { Japanese } & \text { /way way/ }\end{array}$

(Adapted from Rungrojsuwan, 2009:254)

Surprisingly, if a child speaker of EkeGusii is asked to report how a dog barks, they will use gwogwo [ұuoyuo] as an ideophone in the adverb position. Rungrojsuwan (2009) did not account for phonetic similarities in onomatopoeia. Such similarities can only be made possible within explicit onomatopoeia, as a demonstration that regardless of the slight sound variations, the speakers in each language tend to reenact approximately what the dog does; speakers ape the dog, which is here called playing a 'play-back' or 'parrot role' in the words. Therefore, in the cases of implicit onomatopoeia, such similarities are likely to be minimal, though this is better treated as a research agenda.

Although other scholars like Fordyce (1988) and Ma (2018) have their own divisions of onomatopes, their parameters of assessment and analysis are fairly different, suggesting that languages handle lexical material differently. For instance, in Fordyce, onomatopes are either transparent or opaque, and in Ma, either vivid or approximate, but these have more beyond sheer use of terminology. Another interesting of Ma's divisions is that onomatopoeias are either human-voice onomatopoeias or objective sound onomatopoeias, but this obscures a few other delineation; for instance, in EkeGusii, animal sounds could be those produced by the animals themselves like $e$-bi-siriri [e $\beta$ isiriri] 'crickets', or those 
associated with the animal as in the movement of a bird or the lizard (that is if animals are perceived as other objects). Humans generate various voices ranging from vocal and nasal (both voluntary and impulsive) to spontaneous noises associated with the gastro-intestinal system such as bowel movements, and the involuntary noises that occur as a result of humans carrying out their daily activities.

\section{The metaphorical function of onomatopoeic expressions}

Most of the onomatopes in EkeGusii have been applied in other usage where words acquire meanings on the basis of association of features. For instance, the word ebichuchu 'chicks' is commonly transferred to children. A common greeting in EkeGusii is ebichuchu mbuyabire? 'Are the chicks okay?' The respondent usually understands that the concern is to do with the children and gives the appropriate response. When one is carrying out a task in the last minutes, he or she will usually say ekengere kiabugire 'the bell has gone' to mean that they are running out of time. The phrase ogotwang a emeremo literally translated as 'to beat work' is transferred from the onomatopoeic infinitive which has the sound sequence [tuaan] suggestive of the noise associated with beating. Before one gives a speech to an audience, speakers usually clear their throat with sounds that resemble a cough. Therefore, when an amateur speaker is being prepared to speak, they may be told korora ango toigwe [korsra ayyo toizue] literally, 'let's now hear you cough,' to mean 'let's hear you speak'. A young man who is trying to voice his opinion particularly in a political contest may be intimidated by the seniors, especially if they find it unpalatable, with a phrase like abamura bachakire gweturugunkia 'young men have begun their [kpkıdu:dldu:]', to mean that the young men are trying to present themselves as cocks without 'approval' of the seniors. Such remarks are meant to sound pejorative and corrosive for political reasons. Those people who attempt to do distasteful acts or utter offensive words may be threatened with phrases like ntogwancha otosinyorere 'we cannot allow you to urinate on us' or togosaa igaa 'you cannot diarrhoea here'. Such and more other meaning transfers are not based on the iconic nature of the words but on their metaphorical relevance which warrants the meaning extension or what Dofs (2008) terms as 'conventionalization of onomatopes'.

Metaphor, as observed by Evans \& Green (2006:168), is characterized by a schematic form ' $\mathrm{A}$ is B'. In schema mappings, there is a projection of a frame onto particular utterances. For instance, if an elderly person utters the phrase above, ekengere kiabugire

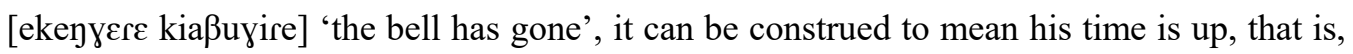
he is about to die. This is understood by matching its components onto those of a timed activity where there is a bell ringer, a stop-watch, the activity's start and end time. In this sense, onomatopes are treated as the SOURCE domain and their metaphorical references as 
the TARGET domains that are understood on the basis of some degree of perceived resemblance.

It should be noted here that the syllable structure, the morphological and syntactic features of phonaesthemes, and onomatopes, in both infinitival and nominal types, may not be pursued since these are true infinitives and nouns, extensively discussed in Cammenga (2002), and Nash (2011). For instance, the infinitival onomatopes are marked by the word-initial prefix /-ko-/, and the final suffix vowel /-a/. Equally, the nominal onomatopes do accommodate the prefixes that mark the semantic-syntactic categories of singular and plural, and display ordinary noun affixation (pre-prefix + class prefix + stem). Cammenga (2002) extensively discusses the syntactic functions of nouns as subjects, objects, verbal complements, prepositional objects, or nominal predicates. In phrases, they will function as heads, and semantically as substantives that name things, persons, places and ideas (Cammenga, 2002:191-192). It would not be worthwhile to pursue such an already handled agenda. Finally, prosodies in EkeGusii onomatopes do not seem iconized, which may not warrant desire for investigation. However, a focused research on these claims will be more conclusive.

\section{Conclusion}

Onomatopoeia is attestable across many languages though in other cases it is considered a fraction of ideophones. In EkeGusii, onomatopoeia is better handled separately from ideophonicity since onomatopes are fully lexicalized in the language unlike ideophones which sometimes may remain individualized and context-bound, and are usually riddled with alien sounds and class wavering characteristics. Several infinitives and nouns have been derived from onomatopoeic roots by clear morphological affixation. In certain cases, nouns appear inherently onomatopoeic since sound-meaning mappings are indirect or implied. It appears convenient to group EkeGusii onomatopes into two types, explicit (or transparent), and implicit (or metonymical). The label opaque may tentatively be considered appropriate since most indirect or implied onomatopes are associative or approximate in terms of sound imitation. Finally, in a number of expressions in EkeGusii, onomatopes achieve metaphoric functions, which though, may vary from usage and signer to another.

$\begin{array}{llll}\text { Abbreviations } & & \\ \text { AUG } & \text { augment (or pre-prefix) } & \text { NOM } & \text { nominal } \\ \text { CAUS } & \text { causative morpheme } & \text { PL } & \text { plural } \\ \text { EXT } & \text { extender morpheme } & \text { REFL } & \text { reflexive morpheme } \\ \text { FV } & \text { final vowel } & \text { SUB } & \text { subject marker }\end{array}$


Onomatopoeic Infinitives and Nouns in EkeGusii: Evidence for imagic and relative iconicity

\section{References}

Assaneo, M. F., J. I. Nichols \& M. A. Trevisan. 2011. The Anatomy of Onomatopoeia [J]. PLoS ONE, 6 (12): e28317.

Bolinger, D. 1949. The Sign is not Arbitrary [J]. Thesaurus: Boletín del Instituto Caro y Cuervo, 5(1-3):52-62.

Bosire, K. M. \& G. K. Machogu. 2013. Authoritative EkeGusii Dictionary: Endabaro endabasiay' EkeGusii [M]. Nairobi: EkeGusii Encyclopedia Project.

Bouissac, P. (ed.). 1998. Encycopedia of Semiotics [M]. Oxford: Oxford University Press, 293-294.

Cammenga, J. 2002. Phonology and Morphology of EkeGusii: A Bantu language of Kenya [M]. Köln: Rüdiger Köppe Verlag.

Chandler, D. 2002. Semiotics: The basics [M]. London: Routledge.

Dai, Q-X. \& X-J. Xu. 1995. Lexicology of Jingpho Language [M]. Beijing: Minzu University of China Press.

Dingemanse, M. 2018. Redrawing the Margins of Language: Lessons from research on ideophones [J]. Glossa: A Journal of General Linguistics, 3(1):4.

Dofs, E. 2008. Onomatopoeia and Iconicity: A comparative study of English and Swedish animal sounds [D]. Bachelors Dissertation. Karlstads: Karlstads University.

Ely, R. 2005. Language and Literacy in the School Years [A]. In J. B. Gleason (ed.). The Development of Language [C]. Boston MA: Allyn \& Bacon, 395-443.

Evans, V. \& M. Green. 2006. Cognitive Linguistics: An introduction [M]. Edinburgh: Edinburgh University Press Ltd.

Fordyce, J. F. 1988. Studies in Sound Symbolism with Special Reference to English [D]. Doctoral Dissertation. University of California Los Angeles.

He, Z-R. 2008. On Memes and Memetics in Language [A]. Special Issue with Papers from the 10th International Conference [C]. (https://www.researchgate.net>publication, accessed 1 June 2020)

Kirtchuk, P. 2011. Onomatopoeia and Phono-iconicity in Hebrew [OL]. (HAL Id: hal-00602819v1. https://hal.archives-ouvertes.fr/hal-00602819v1)

Ma, Q-H. 2018. The Significance of Onomatopoeia in Languagization: From the perspective of sound-meaning relationship under dynamic system principle [J]. Macrolinguistics, 6(1):43-62.

Maeder, C., O. Fischer \& W. J. Herlofsky (eds.). 2005. Outside-in-inside-out: Iconicity in language and literature $[\mathrm{C}]$. Amsterderm: John Benjamins.

Mariera, E. O. (Forthcoming). Prosodic Simultaneity and Iconicity in EkeGusii [D]. Doctoral Dissertation, Kisii University.

Nash, C. M. 2011. Tone in EkeGusii: A description of nominal and verbal tonology [D]. Doctoral Dissertation, University of Califorinia, Los Angeles.

Nöth, W. 2001. Semiotic Foundations of Iconicity in Language and Literature [A]. In O. Fischer \& M. Nänny (eds.), The Motivated Sign (Iconicity in language and literature 2) [C]. Amsterdam, Philadelphia: Benjamins, 17-28.

Peirce, C. S. 1931. Principles of philosophy (Collected Papers of Charles Sanders Peirce. Vol. 1) [C]. Cambridge, MA: Harvard University Press.

Perniss, P., R. L. Thompson \& G. Vigliocco. 2010. Iconicity as a General Property of Language: Evidence from spoken and signed languages [J]. Frontiers in Psychology, (1):1-15.

Pertiwi, D. H. 2015. Translation of Onomatopoeia and Iconicity in Children Storybook: Crocoffein-coffee of friendship by Waitek Ideo and Fitri Kurniwan [D]. Strata One Thesis, State Islamic University Syarif Hidayatullah Jakarta.

Rungrojsuwan, S. 2009. The Non-arbitrary Aspect of Language: The iconicity of onomatopoeic words in Thai [J]. Sky Journal of Linguistics, 22:251-276.

Samarin, W. J. 1965. Perspective on African Ideophones [J]. African Studies, 24(2):117-121.

Schmidtke, D. S., M. Conrad \& A. M. Jacobs. 2014. Phonological Iconicity [J]. Frontiers in Psychology. $5: 1-6$.

Smoll, L. I. 2014. Me:ruru, фoku, and tfitowif: An analysis of ideophones in Katuena (Tunayana) [D]. 


\section{Elijah Omwansa Mariera}

Masters Thesis, Leiden University Centre for Linguistics (LUCL).

van Langendonck, W. 2007. Iconicity [A]. In D. Geeraerts \& H. Cuyckens (eds.). The Oxford Handbook of Cognitive Linguistics [C]. Oxford: Oxford University Press, 394-418.

Wehmeier, S. (ed.). 2000. Oxford Advanced Learners Dictionary (6th edition) [M]. Oxford: Oxford University Press. 